\title{
Impacts of climate change on building energy demands in the intra-Americas region
}

\author{
Moises E. Angeles ${ }^{1}$ (D) • Jorge E. González ${ }^{1}$ - Nazario Ramírez ${ }^{2}$
}

Received: 21 June 2016 / Accepted: 16 May 2017 /Published online: 31 May 2017

(C) The Author(s) 2017. This article is an open access publication

\begin{abstract}
It was recently reported a regional warming in the intra-Americas region where sea surface temperature exhibited increases exceeding $0.15^{\circ} \mathrm{C} /$ decade and an accelerated air temperature rise that could impact building energy demands per capita (EDC). Reanalysis data is used herein to quantify the impacts of these warming trends on EDC. Results of the analysis depict a Southern Greater Antilles and inland South America with a positive annual EDC rate of $1-5 \mathrm{kWh}$ per year. The Intergovernmental Panel on Climate Change (IPCC) Representative Concentration Pathways (RCP) 2.6 and 4.5 scenarios were selected to analyze energy demand changes in the twenty-first century. A multi-model ensemble forecasts an EDC increase of 9.6 and $23 \mathrm{kWh} /$ month in the RCP2.6 and RCP4.5 at the end of the twenty-first century, which may increase average building cooling loads in the region by $7.57 \mathrm{GW}$ (RCP2.6) and $8.15 \mathrm{GW}$ (RCP4.5), respectively. Furthermore, 4 of 9 (RCP2.6) and 7 of 9 (RCP4.5) of the major countries in this region have EDCs ranging between 1887 and $2252 \mathrm{kWh} /$ year at the end of this century. Therefore, increased energy production and improved energy infrastructure will be required to maintain ideal indoor building conditions at the end of the twenty-first century in these tropical coastal regions as consequence of a warmer climate.
\end{abstract}

Moises E. Angeles

mangeles@ccny.cuny.edu

1 Department of Mechanical Engineering and NOAA-CREST, The City College of New York, 140W, New York, NY 10031, USA

2 Department of Industrial Engineering, University of Puerto Rico-Mayaguez, Mayaguez, PR 00680, Puerto Rico

\section{Introduction}

In Tropical coastal cities where fossil energy resources are scarce, the warming environment is a key process that requires attention with regard to regional energy demands. One of such regions is the intra-Americas region (IAR), an area in the tropics that encompasses the Caribbean, Central America, south-central Mexico, and northwestern South America (Curtis 2013) (Fig. 1).

The Caribbean is characterized by a vibrant economic activity, with a total energy per capita of $1251 \mathrm{kWh}$ in 2009 , which was close to half of the total world energy per capita (Irena 2012). Due to inefficiencies in the electrical energy infrastructure, the energy costs in the region are high. For instance, the highest residential electricity cost in 2012 was $25 \mathrm{US}$ cent $/ \mathrm{kWh}$, almost twice the price in the USA (McIntyre et al. 2016). Furthermore, as a result of the warm climate, tropical coastal regions have high energy demands for building air conditioning, often exceeding $50 \%$ of the total energy budget (Edwards et al. 2012). In 2005, the net energy consumption in the residential sector was approximately $35 \%$ of the total energy produced for the case of Puerto Rico (Alva et al. 2005), while in Barbados, the air conditioning energy demand was $48.2 \%$ of the total electrical energy consumed in hotels (McIntyre et al. 2016). Moreover, the US residential and commercial energy demand reached $72 \%$ of the total electrical energy generated in 2013. In addition, the energy consumption for heating, ventilation, and air conditioning (HVAC) is higher than other components in residential and commercial buildings, consuming 26 and $40 \%$ (respectively) of the total electrical energy (U.S. Department of Energy 2009; U.S. Environmental Protection Agency 2015). Consequently, HVAC energy per capita consumption is a suitable indicator of energy consumption in buildings and of overall energy demand in most tropical countries. Energy demand 


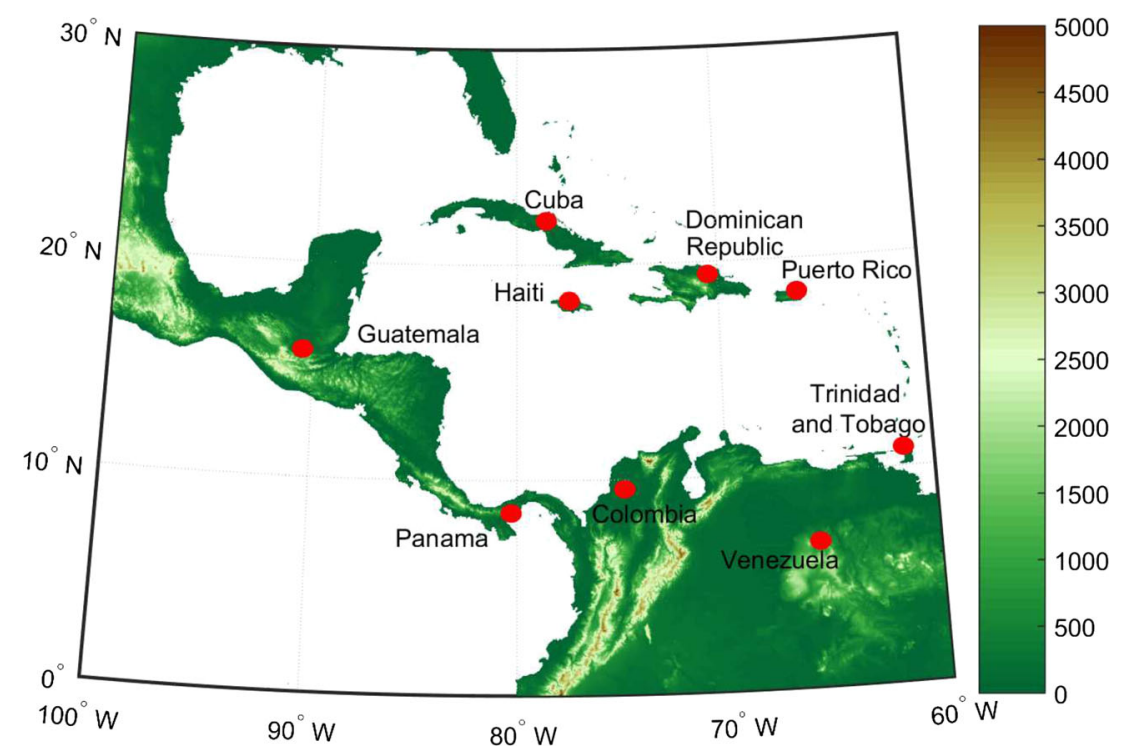

Fig. 1 Intra-Americas region with major countries. High mountains are shown in Southern Mexico, Central America, and Northern South America

is a key mitigating factor geared towards protecting human health and economic activities in a warming climate.

The work herein focuses on determining the possible implications of regional warming on energy demands per capita in the IAR. Hence, a key guiding question of the research is how may EDC in the IAR change as a result of a warmer twenty-first century?

The main objective of this work is to quantify the future EDC necessary to mitigate regional warming effects on human health. To accomplish this goal, the current observed and simulated EDC and near-term tendencies are analyzed to identify the current and future regional warming impacts over IAR energy demand per capita.

A regional warming trend in Central America and the Caribbean region has been recently been reported, with an intensification in the Atlantic Warm Pool (Glenn et al. 2015). This regional warming exhibits a positive annual sea surface temperature (SST) trend of $0.015{ }^{\circ} \mathrm{C}$ per year from 1982 to 2012. As a result of this, warmer air advection could develop and cause enhanced warming at the lower atmospheric levels and vertical convection intensification. Furthermore, SST greater than $26^{\circ} \mathrm{C}$ incentivizes rainfall while if the SSTs exceed $29.5^{\circ} \mathrm{C}$, less rainfall may be produced (Folkins and Braun 2003) leading to an uncomfortable environment. This warming trend could intensify extreme events such as heat waves and droughts. Consequently, an accelerated air temperature rise will cause larger building EDCs to mitigate the regional warming effects. For instance, it has shown that a $0.56{ }^{\circ} \mathrm{C}$ increase in temperatures during the summer can increase building cooling loads by 1.5 to $2 \%$ (Akbari et al. 1992). In terms of energy density, it was reported an energy density increase of $90 \mathrm{~W} / \mathrm{m}^{2}$ in New York City when extreme heat events occurred (Gutiérrez et al. 2013). Land use for urbanization is an added factor in energy demands in large cities including those in the IAR (Gonzalez et al. 2005, 2013; Comarazamy et al. 2013).

There have been attempts to project energy consumption at the middle of the twenty-first century using a multilinear regression technique which incorporates electricity and gas consumption along with air temperature and relative humidity (RH). Resulting projections for the United Kingdom (20302059) indicate that energy consumption will increase by $5.5 \%$ while gas consumption will decrease by $28 \%$ (Braun et al. 2014). A long-term projection of Australian energy consumption calculated via the dynamic partial equilibrium model (E4cat) showed that the total primary energy consumption increased from 2015 at approximate rate of $1 \%$ per year up until 2050 (Calder 2014). Furthermore, there is a gap in the scientific reports on the projection of EDC in the IAR at the twenty-first century and in using general circulation models (GCMs). This work aims to satisfy this void in the literature.

Past works by the authors included projections for renewable energy resources along the twenty-first century and in the Caribbean (Angeles et al. 2010b). The present work builds from these past efforts by focusing on energy demands in the building sector. We present a new method to quantify building energy demands per capita due to a warming climate and also to predict energy demands per capita along the twenty-first century.

The remaining of the article is organized as follows: a brief description of the general circulation models will be presented along with the methodology used in this research. Posteriorly, current observed and simulated energy demand climatology, along with near-term tendency, is investigated. Finally, future projections using GCMs are studied to accomplish the main goals of this research. 


\section{Methodology}

In this section, a method involving the utilization of historical reanalysis records and numerical models to project building EDC is described. In addition, the non-parametric Mann-Kendall test was implemented to determine trends in observed data until 2013 and future projections. Lastly, numerical experiments based on selected IPCC scenarios are described.

\subsection{Reanalysis and energy data}

The National Oceanic and Atmospheric Administration (NOAA) Optimum Interpolation SST (OISST) $1^{\circ}$ resolution product was selected to analyze SST trends and climatology in the IAR (1982-2013). In addition, the Climate Prediction Centers-Merged Analysis of Precipitation (CMAP) $2.5^{\circ}$ resolution product was used to calculate the regional rainfall climatology from 1980 to 2013. The atmospheric fields of interest, the surface air temperature, and $\mathrm{RH}$ were retrieved from the National Center for Environmental Prediction (NCEP) reanalysis dataset (also at $2.5^{\circ}$ resolution). These variables are key to estimate the heat index (HI), human discomfort index (HDI), and the EDC (1980-2013) required to maintain adequate indoor building conditions to mitigate the regional warming impact. Nine major countries within the IAR, including the Dominican Republic, Haiti, Cuba, Puerto Rico, Panama, Trinidad and Tobago, Venezuela, Colombia, and Guatemala were selected based on population size and location within and around the Caribbean warm pool. Electrical energy consumption for each of the nine sites in $\mathrm{kWh}$ per capita was attained from the World Bank dataset (The World Bank 2015).

\subsection{General circulation models-CMIP5 project}

According to the IPCC, the global warming was correlated with the $\mathrm{CO}_{2}$ increase attributed mostly to the burning of fossil fuels (IPCC 2013). To account for new climate change understanding, the IPCC has replaced old scenarios with the representative concentration pathways (RCPs). The RCP2.6 and RCP4.5 scenarios were selected in this research following the Paris agreement, which aims to maintain a global air temperature rise well below the $2{ }^{\circ} \mathrm{C}$ (Stavins and Stowe 2016). Relative to the average from 1850 to 1900 , the RCP2.6 scenario predicts a global air temperature rise unlikely to exceed $2{ }^{\circ} \mathrm{C}$ at the end of the twenty-first century, while the RCP4.5 scenario is more likely than not to exceed $2{ }^{\circ} \mathrm{C}$ (Moss et al. 2008; IPCC 2013).

The IPCC scenarios were adopted as a standard radiative forcing in the fifth phase of the Coupled Model Intercomparison Project (CMPI5). CMIP5 provides a credible multi-model dataset, taking time-varying greenhouse gas concentration, carbon cycle, and dynamical vegetation into account. In near-term simulations, CMIP5 models could predict climate changes and tropical cyclones, while long-term simulations provide climate projections in accordance with changes in the atmospheric greenhouse gas concentration and land cover (Taylor et al. 2012). Under this framework, four GCMs were selected in this study to account for climate modeling uncertainty. These include the Community Climate System Model version 4 (CCSM4); the Community Earth System Model; version 1 (CESM1)-Biogeochemistry (CESM1-BGC); the CESM1Community Atmospheric Model version 5 (CESM1-CAM5); and the CESM1-Whole Atmosphere Community Climate Model (CESM1-WACCM), which incorporates ozone layer hole. These models have a uniform resolution of $0.94^{\circ}$ in latitude and $1.25^{\circ}$ in longitude. GCMs have improved physical parameterizations and the vertical resolution, with 26 vertical layers (Gent et al. 2011; Holland et al. 2012), and due to these improvements, CCSM4 is able to reproduce more realistic El NiñoSouthern Oscillation and tropical rainfall frequency distribution (Gent et al. 2011).

A mean multi-model ensemble is used in this work to account for modeling uncertainties and consists of averaging all GCM atmospheric variables for the same IPCC scenario to obtain representative time series of atmospheric variables. CCSM4, CESM1-BGC, CESM1CAM5, and CESM1-WACCM were considered to calculate the mean multi-model ensemble because they have identical spatial resolution with reduced numerical discrepancies compared to coarser resolution models. Furthermore, spatial distributions of RH, HI, and EDC will be analyzed using the CCSM4 model. Ninety-four (94) years of simulation, from 2006 to 2099, were divided into three climatological periods. The "current climate" period includes 2006 to 2020. This current climate will be used as a comparative baseline against the future climates. The "first future climate" period is from 2041 to 2060, and the "second future climate" period covers 2081 to 2099. The cooling and ventilation EDC is calculated for the three climate periods in the IAR.

\subsection{Heat index, human discomfort index, energy per capita}

The National Weather Service provides an HI chart as a function of temperature and relative humidity, known as Steadman's table (Steadman 1979; NOAA 2014), and representing the heat-stress danger (Stull 2000). At very high temperatures $\left(40{ }^{\circ} \mathrm{C}\right)$, the $\mathrm{HI}$ reflects extreme danger for heatrelated illness even for low RH. In addition, the Rothfusz's regression represents the Steadman's table and it is widely accepted by the scientific community with an error of $\pm 0.72{ }^{\circ} \mathrm{C}$ (Anderson et al. 2013; NWS 2014): 


$$
\begin{aligned}
& H I=-42.379+2.04901523 \times T+10.14333127 \\
& \times R H \quad-0.22475541 \times T \times R H-6.83783 \times 10^{-3} \\
& \times T^{2} \quad-5.481717 \times 10^{-2} \times R H^{2}+1.22874 \times 10^{-3} \\
& \times T^{2} \times R H \quad+8.5282 \times 10^{-4} \times T \\
& \times R H^{2}-1.99 \times 10^{-6} \times T^{2} \times R H^{2}
\end{aligned}
$$

This equation is adjusted when the air temperature is high, and the RH is extremely low and high (NWS 2014).

There are many human discomfort index definitions using dry and wet bulb temperatures along with black globe temperature (Moran et al. 2001; Tejeda and Garcia 2002; Mohan et al. 2014); however, these definitions have limitations because of the difficulty involved in calculating the black global temperature (Moran et al. 2001; Epstein and Moran 2006). Other methods, such as Thom's discomfort index, works with temperatures ranging from 24 to $27^{\circ} \mathrm{C}$ and as a result is more appropriate for mid-latitude regions and relative cold climates. In tropical regions, populations feel a higher degree of comfort at higher air temperatures due to climate adaptation (Mohan et al. 2014), therefore requiring a new human discomfort index (HDI) for tropical regions based on population real thermal feeling, and applicable for different climate regions. In the present work, the following HDI is proposed:

$\mathrm{HDI}=\frac{H I-H I_{\text {ref }}}{H I_{\text {ref }}}$

where $H I_{r e f}$ is heat index at the reference comfort level $22.2{ }^{\circ} \mathrm{C}$ and $50 \% \mathrm{RH}$. Positive HDI represents cooling state conditions, while negative HDI represents a warming state. These conditions allow for the identification of regions with demands for HVAC systems.

Typical indoor building design conditions require an air temperature of $22.2{ }^{\circ} \mathrm{C}, 50 \% \mathrm{RH}$, and $25.5 \mathrm{~m}^{3} / \mathrm{h}(15 \mathrm{cfm})$ outside air per person to dilute odors from human bioeffluents and replace the consumed oxygen (Persily et al. 2003; ASHRAE Press 2007). The energy per capita (in kW) required for this typical ventilation condition is thus given by

Energy $=\frac{25.5^{m^{3}} /{ }_{h r}^{*} \rho_{\text {air }} *\left(h_{e n v}-h_{r e f}\right)}{3600}$

where $h_{e n v}$ is thermodynamic enthalpy calculated using the mixing ratio, 3600 is the unit conversion from $\mathrm{kJ} / \mathrm{h}$ to $\mathrm{kW}$, and the reference level enthalpy is given by $h_{r e f}=62.8 \mathrm{~kJ} /$ $\mathrm{kg}$. It is assumed herein that energy required for human comfort is a main indicator of energy demands in buildings, which may be the case for most IAR countries, where energy from buildings account for nearly $50 \%$ of the total energy budget (Edwards et al. 2012).
Using NCEP Reanalysis data, the annual EDCs are approximated in this research for the nine IAR countries of interest and compared with the current climate EDC simulated by the GCMs. In addition, trends were calculated for energy demand per capita and the electrical energy consumption in the major IAR countries. The non-parametric Mann-Kendall test was selected to determine the trend statistical significance, based on its probability distribution-free characteristic (Zhang et al. 2011; Rahman and Begum 2013; Carmona and Poveda 2014).

\section{Results}

In this section, the IAR climatology and trends analyses of the heat index, HDI, and energy demand per capita are presented for present time and GCM projections.

\subsection{Intra-Americas climatology}

Multiple dynamic atmospheric processes converge in the IAR, driving the rainfall, air temperature, and the atmospheric water content. The North Atlantic High Pressure System (NAHPS) interacts with the Caribbean low level jet, generating sinking dry air and low-level moisture advection in the rainy season (Moran 2002; Gamble and Curtis 2008). In addition, stronger trade winds are related with lower SST, causing a drier Caribbean (Mapes et al. 2005; Gamble and Curtis 2008). During the rainy season, a deep thermal convection is developed when a warmer Caribbean sea meets with low vertical wind shear (VWS), intensifying the rainfall generation (Angeles et al. 2007, 2010a; Glenn et al. 2015). At the same time, descending air coming from Central America could inhibit this vertical convection and hindering rainfall formation (Magaña and Caetano 2005; Gamble and Curtis 2008). Furthermore, local wind divergence causes sinking air, countervailing vertical convection and affecting rainfall generation (Curtis and Gamble 2008; Gamble and Curtis 2008). These complex processes lead to a bimodal rainfall pattern in the region (see Fig. 2a). This bimodal signature is characterized by rainfall decrease in July and divides the rainy season into early rainfall season (ERS) and late rainfall season (LRS). ERS is defined from April to July and LRS from August to November (Taylor et al. 2002; Magaña and Caetano 2005; Gamble and Curtis 2008; Angeles et al. 2010a; Curtis 2013). Furthermore, the dry season (DS) spans from December to March and it is characterized by low rainfall activity (Taylor et al. 2002; Angeles et al. 2010a).

The Caribbean climatology depicts SST intensification from ERS to LRS, where SST is above the threshold for convection $\left(26^{\circ} \mathrm{C}\right)$ as shown in Fig. 2b. An annual SST time series analysis for the IAR indicates a regional warming trend of $0.01{ }^{\circ} \mathrm{C}$ per year (see Fig. 2c). Across the region, the higher annual increasing rate is located in the main development region (MDR, 0.01- 

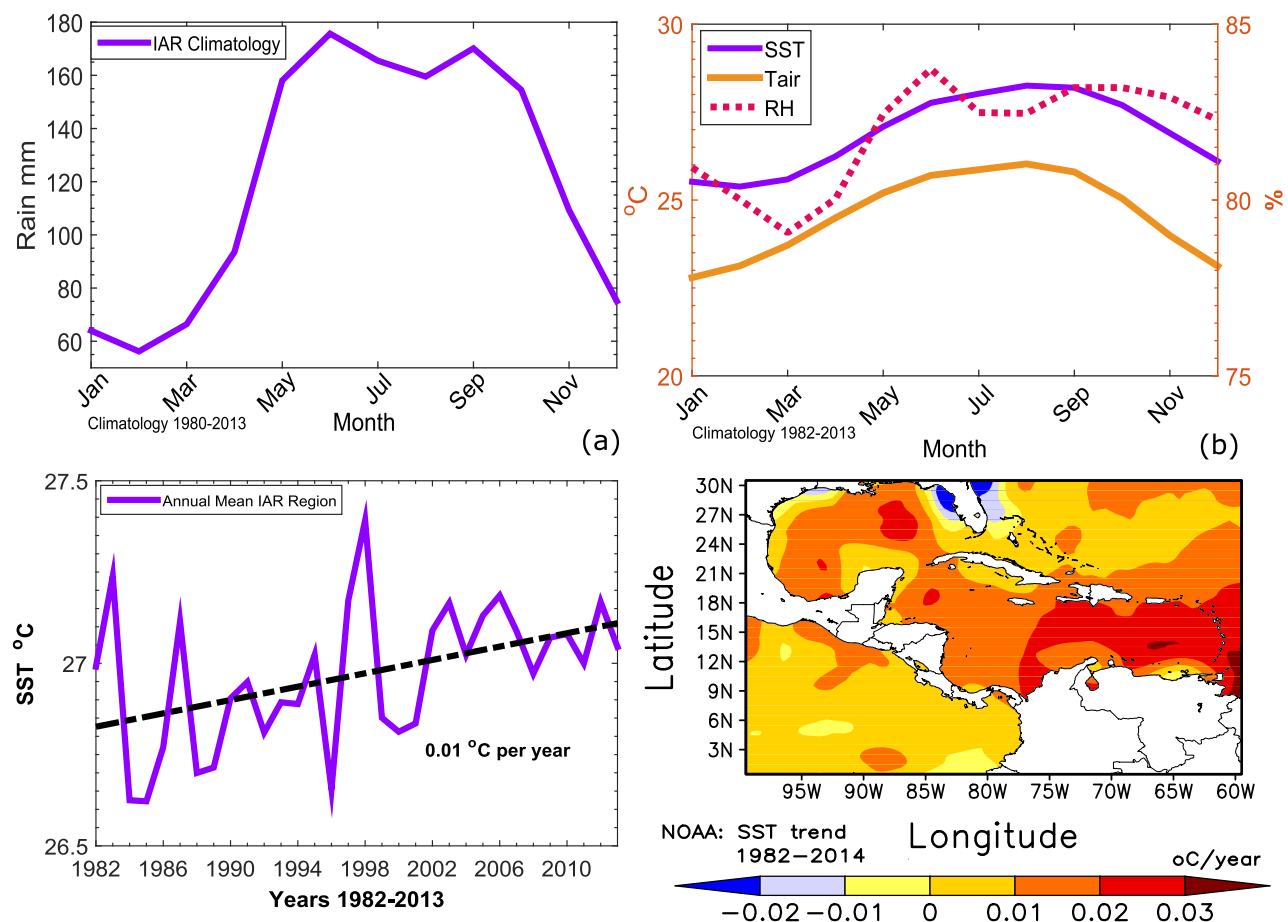

(c)

Fig. 2 IAR climatology 1980-2013 using CMAP data for a rainfall and NCEP Reanalysis data for b SST, air temperature, relative humidity, c SST annual near-term, and $\mathbf{d}$ SST annual trend in ${ }^{\circ} \mathrm{C}$ per year

$0.03{ }^{\circ} \mathrm{C}$ per year), where the Lesser Antilles and the Colombian coastline exhibit larger warming rates with $0.03{ }^{\circ} \mathrm{C}$ per year (see Fig. 2d). At the same time, warmer air temperature is shown over the region and occurs due to the confluence of high SST and warm advection in the MDR (see Fig. 2b). Additionally, the warmer region leads to intense evaporation and enhanced vertical convection, causing higher moisture content in the atmosphere expressed as relative humidity. Consequently, the $\mathrm{RH}$ climatology shows a bimodal pattern (see Fig. 2b).

The warmer and moister atmosphere drives the HI climatology, with LRS being the warmest season. During LRS, the $\mathrm{HI}$ peak is observed in August with a mean value of $28.4^{\circ} \mathrm{C}$ (see Fig. 3a). Moreover, the areas with maximum heat index define the Greater Antilles, South American's Caribbean coastline, Central America coastline, and Yucatán peninsula as regions of caution $\left(28-32{ }^{\circ} \mathrm{C}\right)$ where sunstroke, heat exhaustion, or fatigue could affect the population health (see Fig. 3b). HDI is directly related to HI, following the same climatological pattern. The maximum HDI is observed during August with a peak value of 0.17 (Fig. 3a). During LRS, highest cooling needs impact the entire Caribbean, while a warming need is observed in the Sierra Madre Oriental, Mexico, and the Central and Western mountain range in Colombia. The Greater and Lesser Antilles are the regions with higher HDI, ranging from 0.16 to 0.24 (Fig. 3c). On the other hand, the annual HI and HDI do not have trends with statistical significance but rather a fluctuation around the annual mean value of $26.1{ }^{\circ} \mathrm{C}$ and 0.11 , respectively (see
Fig. 3d). Therefore, from a climatological point of view, the IAR is a region with energy need for building cooling.

\subsection{Current observed environmental energy demand}

EDC for air conditioning across the IAR is analyzed by studying the regional climatology and annual trends (1980-2013). In addition, the observed annual total electrical energy consumption per capita for several IAR countries are contrasted with the EDC calculated from reanalysis data.

The monthly climatological EDC averaged over the entire IAR from 1980 to 2013 indicates a maximum energy requirement in August following the highest HI and HDI, reaching $169 \mathrm{kWh}$ per capita and per month in the LRS (see Fig. 4a). On the other hand, the annual EDC for HVAC averaged through the IAR is calculated using the monthly climatology values and it is equal to $1608.5 \mathrm{kWh}$ per year. Furthermore, the total of number of inhabitants in this region was $114.1 \mathrm{M}$ in 2013 according to the World Bank. This means that the total power demand for cooling in buildings in the region is approximately $21 \mathrm{GW}$.

Seasonal climatological spatial distribution for EDC was calculated over the IAR. In the LRS, the Greater Antilles exhibits the highest EDC (150-200 kWh per month), where the Dominican Republic energy demands fluctuate between 150 and $175 \mathrm{kWh}$ per capita and per month. The South American's Caribbean coastline follows the same pattern as the Greater Antilles, while Panama and Colombia coastlines require the largest energy per capita for HVAC (175-200 kWh 

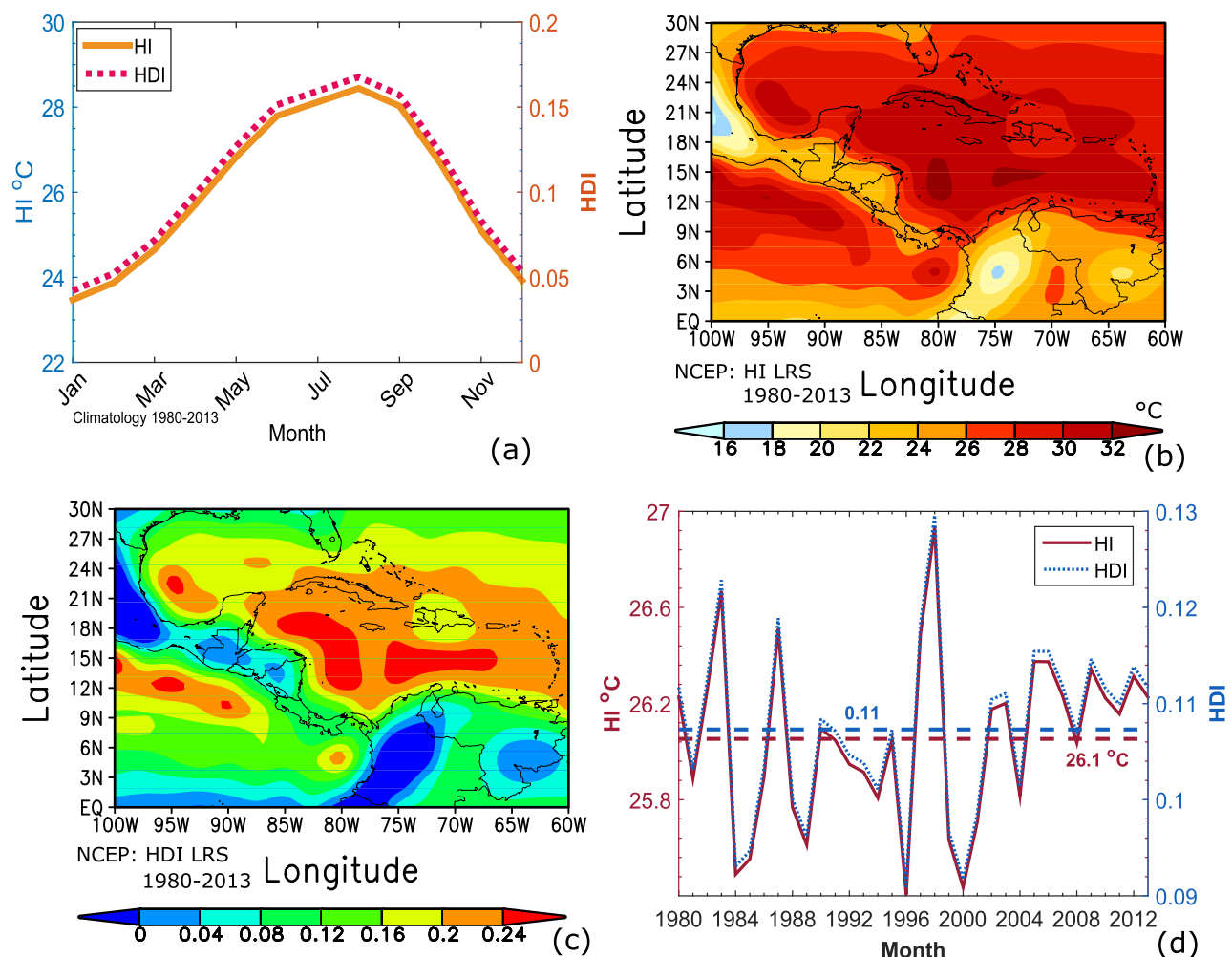

Fig. 3 IAR climatology 1980-2013 using NCEP Reanalysis data for a heat index and HDI, b HI climatology at late rainfall season, $\mathbf{c}$ HDI climatology at late rainfall season, and $\mathbf{d}$ HDI and HI trend from 1980 to 2013
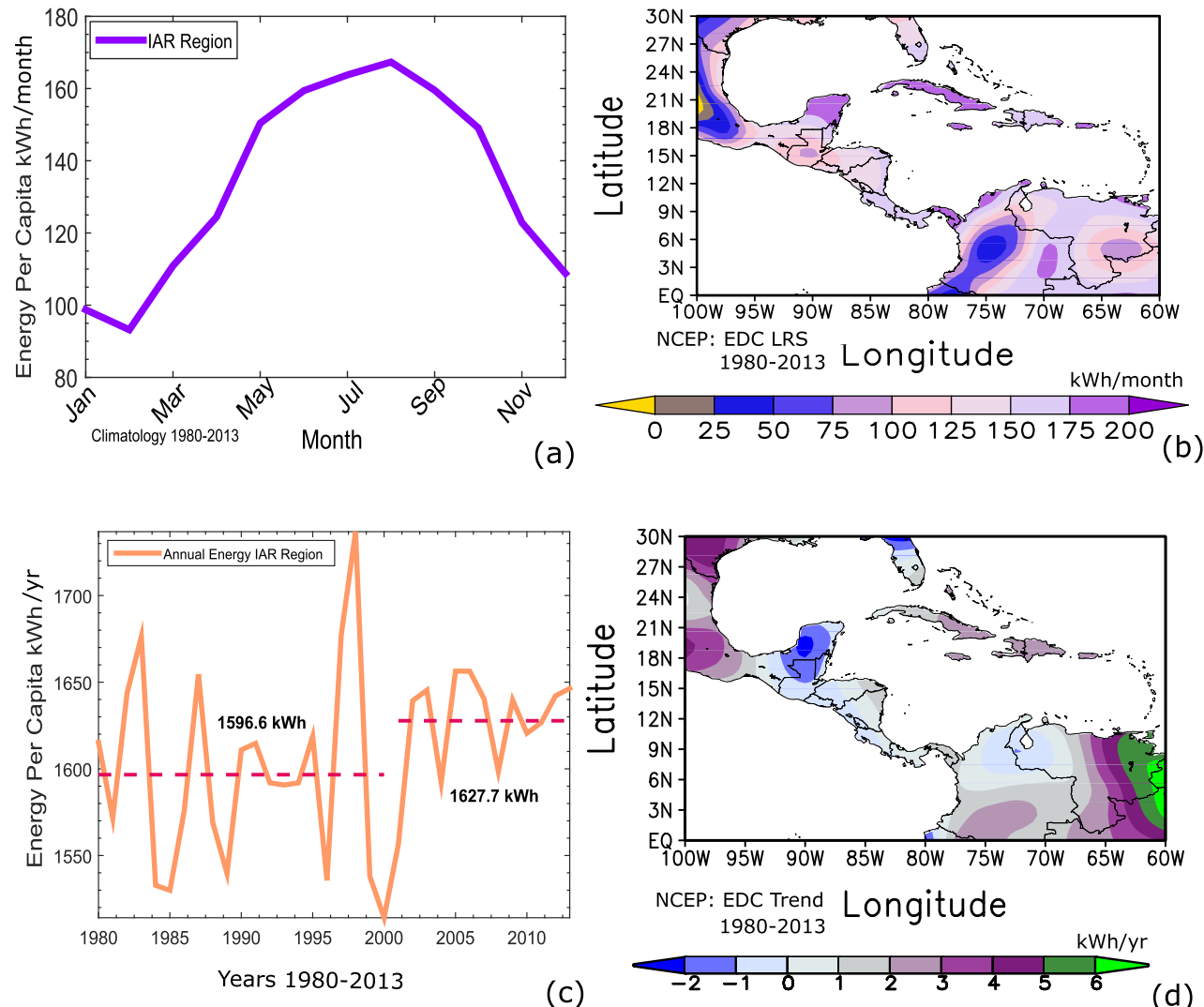

Fig. 4 NCEP data analysis for EDC. a IAR climatology-kWh/month. b Spatial distribution at LRS-kWh/month. c Annual near-term over IAR-kWh/ year. d Annual energy per capita trend in $\mathrm{kWh} /$ year 
per month). Northeastern Mexico is characterized by low (or even zero) EDC due to the Sierra Madre Oriental elevation (3700 $\mathrm{m}$ above sea level), while the Yucatán peninsula has energy demands similar to the Greater Antilles (see Fig. 4b).

The annual EDC time series does not show a significant trend but rather a fluctuation around mean values. Since the 2000 s, the variability has decreased; however, there is an increase in the annual mean value of $31.1 \mathrm{kWh}$ per capita with respect to 1980-2000 (see Fig. 4c). This time variation since the year 2000 follows the fast intensification of SST and HI.

The annual tendency is disaggregated across the IAR to identify the regions with variability and annual trends. The Caribbean Sea along with the Southern Greater Antilles (Dominican Republic and Puerto Rico) shows an annual positive rate of change of $2-3 \mathrm{kWh}$ per year ( $p$ value less than 0.05). In a similar way, inland South America has a positive trend varying between 1 and $5 \mathrm{kWh}$ per year, with the exception of the Northern South America where variability is observed. Southern Mexico and Central America do not present a clear trend (see Fig. 4d); however, Panama and Central Mexico present significant trends, ranging from 2 to $4 \mathrm{kWh}$ per year. Therefore, the IAR is turning into a region with increasing energy demand per capita for HVAC systems.

EDC monthly climatology was calculated for major countries in the IAR. During the LRS, the largest HVAC energy per capita requirement is observed in Cuba (205.7 kWh per month) while the lowest is detected in Guatemala (107.4 kWh per month). Puerto Rico, the Dominican Republic, Trinidad and Tobago, and the Caribbean coast of Colombia have the second highest energy requirements (171-191 kWh per capita and per month, see Fig. 5a). The near-term trend of EDC shows that the Caribbean coast of Colombia, Panama, and Trinidad and Tobago demand the maximum total annual energy per capita (2000-2300 kWh per year) due to the Atlantic warm pool impact in this region (see Fig. 5b). Puerto Rico and the Dominican Republic have lower energy requirements with similar patterns due to easterly winds, ranging from $1750 \mathrm{kWh}$ in the Dominican Republic to $1900 \mathrm{kWh}$ per year in Puerto Rico. Seven of nine countries studied have higher annual EDC (1750-2110 kWh/year), while the lowest one is observed in Guatemala. Trinidad and Tobago, Puerto Rico, the Dominican Republic, and Haití have significant trends, with the largest rate of change in Trinidad and Tobago $(6.1 \mathrm{kWh}$ per year), followed by Puerto Rico (3.0 kWh per year), the Dominican Republic (2.5 kWh per year), and Haití (2.6 kWh per year). The remaining countries do not show relevant trends.

The measured total annual electrical energy consumption per capita (The World Bank 2015) yields positive linear annual trends for all major IAR countries, with values between 12 and $137 \mathrm{kWh}$ per year with the exception of Haiti and Colombia, where negative trends were noticed during the last 12 years $(-0.7$ and $-14 \mathrm{kWh}$ per year, respectively). Trinidad and Tobago and Puerto Rico have the largest trends (137 and
$113 \mathrm{kWh}$ per year) along with the largest energy per capita consumption in the year 2007 (5668.9 and $5691.8 \mathrm{kWh}$ per year, respectively) as shown in Fig. 5c. This may be due to the large energy requirements for gas-related industrial activities in Trinidad and Tobago and high energy consumption by the population in Puerto Rico. A population emigration from 2008 sparked by economic recession caused a noticeable electrical energy consumption reduction in Puerto Rico (see Fig. 5c). All other IAR countries show lower total energy per capita consumption than the required to maintain adequate indoor building environmental conditions (see Fig. 5b, c). Haiti has the lowest energy consumption in the region, even decreasing since 1990. During this period, the IAR is warming with higher SST, and heat index, leading to the highest HDI values. Although Haiti has the lowest energy consumption, it is among the countries with the highest energy per capita requirement.

\subsection{Simulated environmental energy demands under current climate}

Low numerical errors were calculated (1-5\%) when numerical GCM results were contrasted against NCEP data (see Fig. 6a). GCMs simulate the highest air temperature and relative humidity values during the LRS in scenarios RCP2.6 and RCP4.5. In addition, from 2006 to 2020, both scenarios have a very similar climatology because the radiative forcing paths are very close (see Fig. 6b). Thereby, in both scenarios, the geographical distribution of main atmospheric variables simulated using the CCSM4 model show low RH concentrated in Northern South America and Northern Mexico during the LRS. Comparatively, the Caribbean, Central America, and inland Colombia have higher RH. CCSM4 therefore simulates a high-caution human health region with HIs between 32 and $34{ }^{\circ} \mathrm{C}$ in the Yucatan Peninsula and the Central American and Colombia coastlines and ranging from 30 to $32{ }^{\circ} \mathrm{C}$ in the Greater Antilles (see Fig. 6c, d).

The EDC monthly climatology needed to relieve the harmful health effect of intense hot days shows the highest peak in August (185 kWh per month), depicting the IAR as a region with a permanent energy requirement from May to September to maintain optimum indoor environmental conditions in scenarios RCP2.6 and RCP4.5 (see Fig. 7a). The seasonal energy per capita demand in both scenarios and over Greater Antilles evolves from a low energy requirement during the dry season (120 kWh per month) to about $200 \mathrm{kWh}$ per month during the LRS. In the LRS, CCSM4 predicts a similar energy per capita requirement to observed data in the Dominican Republic, with values of approximately $160-180 \mathrm{kWh}$ per month. The Caribbean coastlines of Panama and Colombia follow the same patterns than the Greater Antilles, requiring energy from 180 to $200 \mathrm{kWh}$ per capita per month. In Colombia, the central and western mountain ranges have lower energy requirements for HVAC ranging from 20 to $60 \mathrm{kWh}$ per month and reaching 

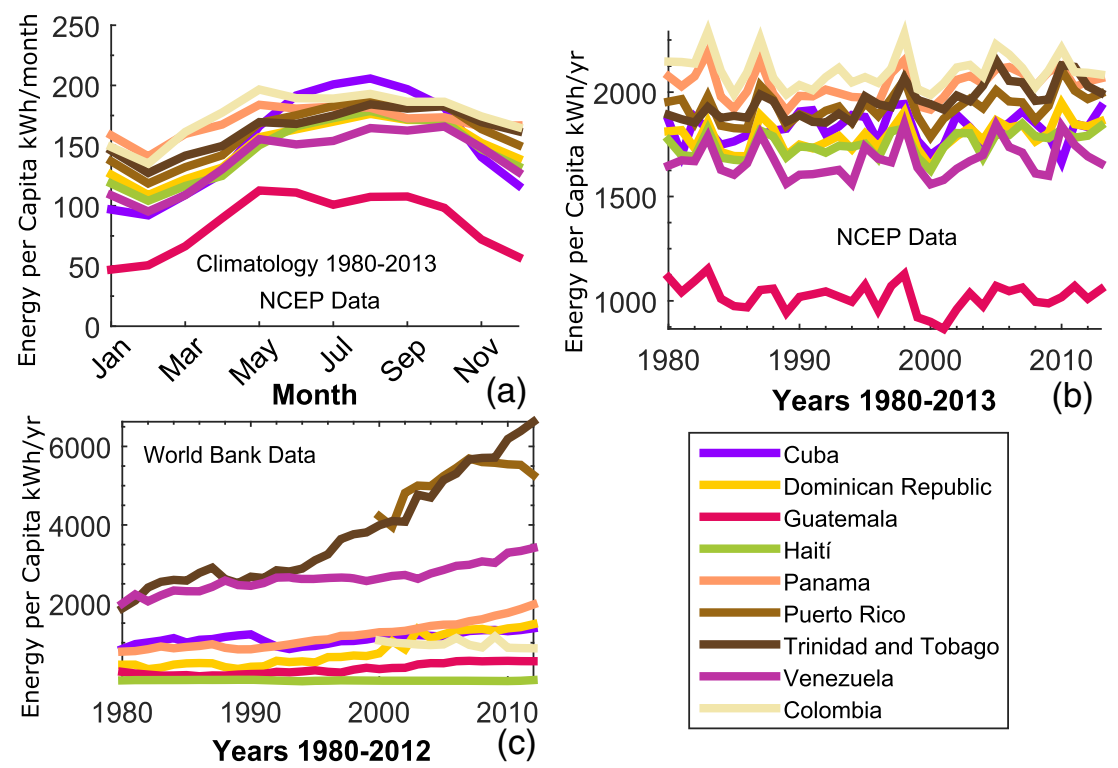

Fig. 5 NCEP data analysis for a climatological monthly energy per capita for HVAC-kWh/month, b annual energy per capita demand per country for building environmental (kWh/year), and $\mathbf{c}$ total electrical energy consumption per capita reported from World Bank kWh/year (The World Bank 2015)

zero energy demand at the highest elevation. Likewise, the Sierra Madre Occidental's Mountain range in Mexico is simulated with zero energy demand at the highest elevation (see Fig. 7b), while the Yucatán peninsula requires EDC similar to the Greater Antilles (180-200 kWh per month).
The annual energy demand per capita averaged over the IAR shows a clear increasing trend of $3.9 \mathrm{kWh}$ per year in the scenario RCP4.5 during the first 15 years of simulation (20062020), while the RCP2.6 scenario does not have a trend, but rather a fluctuation around the annual mean value of $1659.8 \mathrm{kWh}$ (see Fig. 8a). In Fig. 8b, the time variation of the
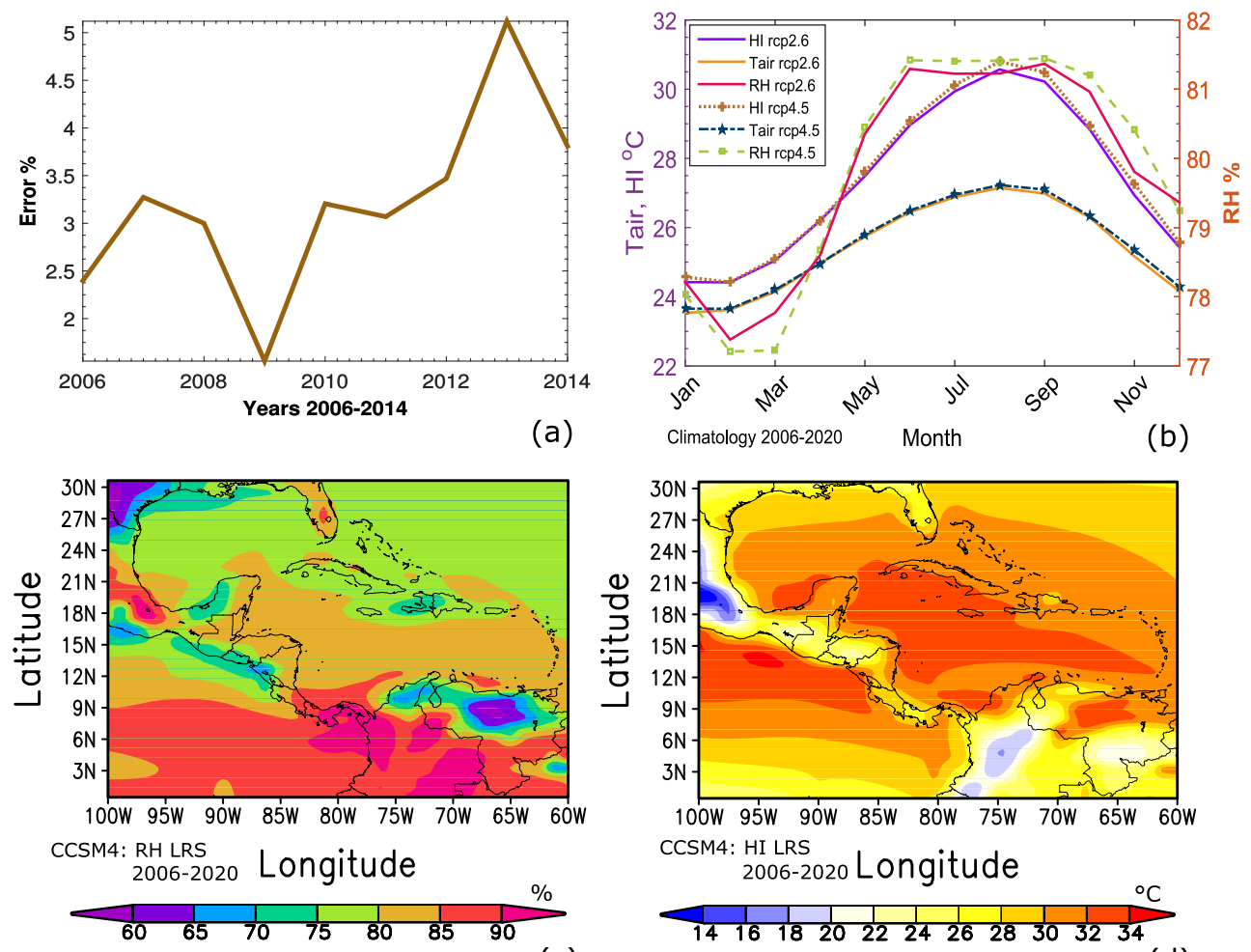

(c)

Fig. 6 a GCMs ensemble error for heat index when compared with NCEP data. b Climatology for air temperature, relative humidity, and heat index using multi-model ensemble. Spatial distribution using CCSM4 for $\mathbf{c}$ relative humidity and $\mathbf{d}$ heat index in the LRS 


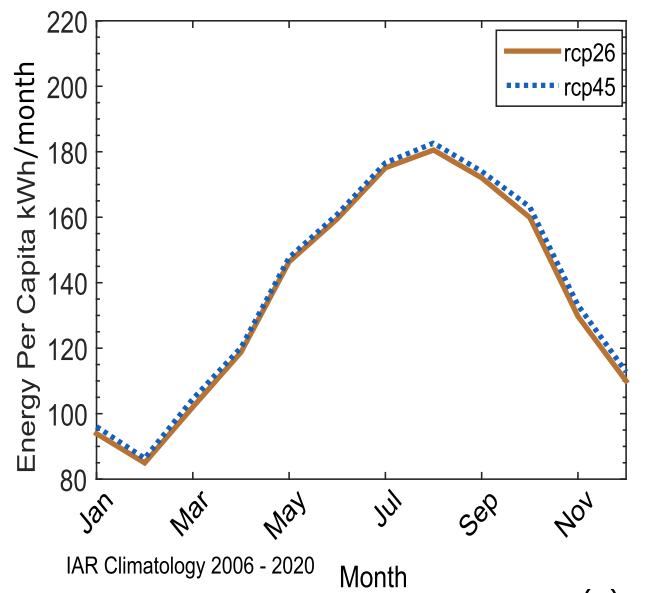

(a)

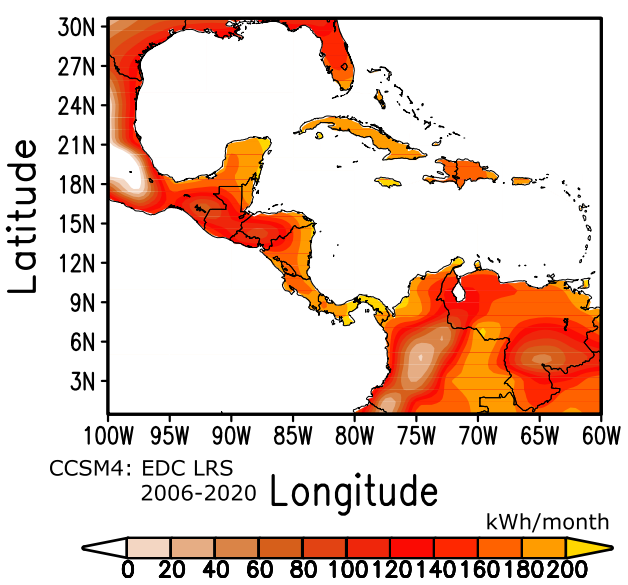

(b)

Fig 7 Current climatology (2006-2020) for a monthly energy demand per capita (kWh/month) using multi-model ensemble and b LRS seasonal climatology over the IAR region provided by CCSM4 $(\mathrm{kWh} / \mathrm{month})$

annual energy per capita simulated by the GCMs for both scenarios follows the amount of energy demand per countries obtained using NCEP Reanalysis data. The simulated and observed energy per capita comparison indicates an error fluctuating between 0.33 and $14 \%$, with the exception of Venezuela and Colombia, nations with errors as high as 40 and $16 \%$, respectively. All countries are simulated with positive rate of change and suitable statistical significance except Colombia, where a fluctuation around mean values was detected. On average, the simulated energy requirement to satisfy the HVAC system demand in buildings and for the major countries will increase at a rate of $3.3 \mathrm{kWh}$ per year during the years 2006 to 2020 .

\subsection{Future projections of environmental energy demand}

The mean multi-model ensemble for the twenty-first century indicates a continuous positive trend for $\mathrm{HI}$ with $0.3{ }^{\circ} \mathrm{C}$ per decade in the scenario RCP4.5. The scenario RCP2.6 shows a trend until the middle of the century $\left(0.28{ }^{\circ} \mathrm{C}\right.$ per decade) for later oscillation without trend around the annual mean of $27.8^{\circ} \mathrm{C}$. At the same time, the HDI has a positive trend, increasing at a rate of 0.008 per decade in RCP4.5 and 0.007 per decade in RCP2.6 (2006-2050). The annual energy per capita demand reflects these positive trends, increasing at a rate of $38 \mathrm{kWh}$ per decade in RCP4.5 and $36 \mathrm{kWh}$ per decade in RCP2.6 during the first 45 years (see Fig. 9). According to the RCP4.5 scenario, the IAR will become warmer, increasing the likelihood of intense heat wave events and requiring more energy to keep human comfort levels at the end of the twenty-first century. In contrast, the scenario RCP2.6 depicts a clear stabilization tendency after 2050 with an annual mean value of $1749.7 \mathrm{kWh}$.

Differences between the two "future climates" and the current climate are calculated using a mean multi-model ensemble to quantify the future climate change. In the scenario RCP4.5, the first future climate alludes to an energy per capita demand increase of about $15 \mathrm{kWh}$ per month with respect to the current climate. The second future climate period, close to the end of the twenty-first century, shows a stronger intensification in the energy requirement for air conditioning systems, reaching anomalies of around $23 \mathrm{kWh}$ per month. Furthermore, the scenario RCP2.6 does not exhibit significant changes in the EDC when the "first and second future climates" are
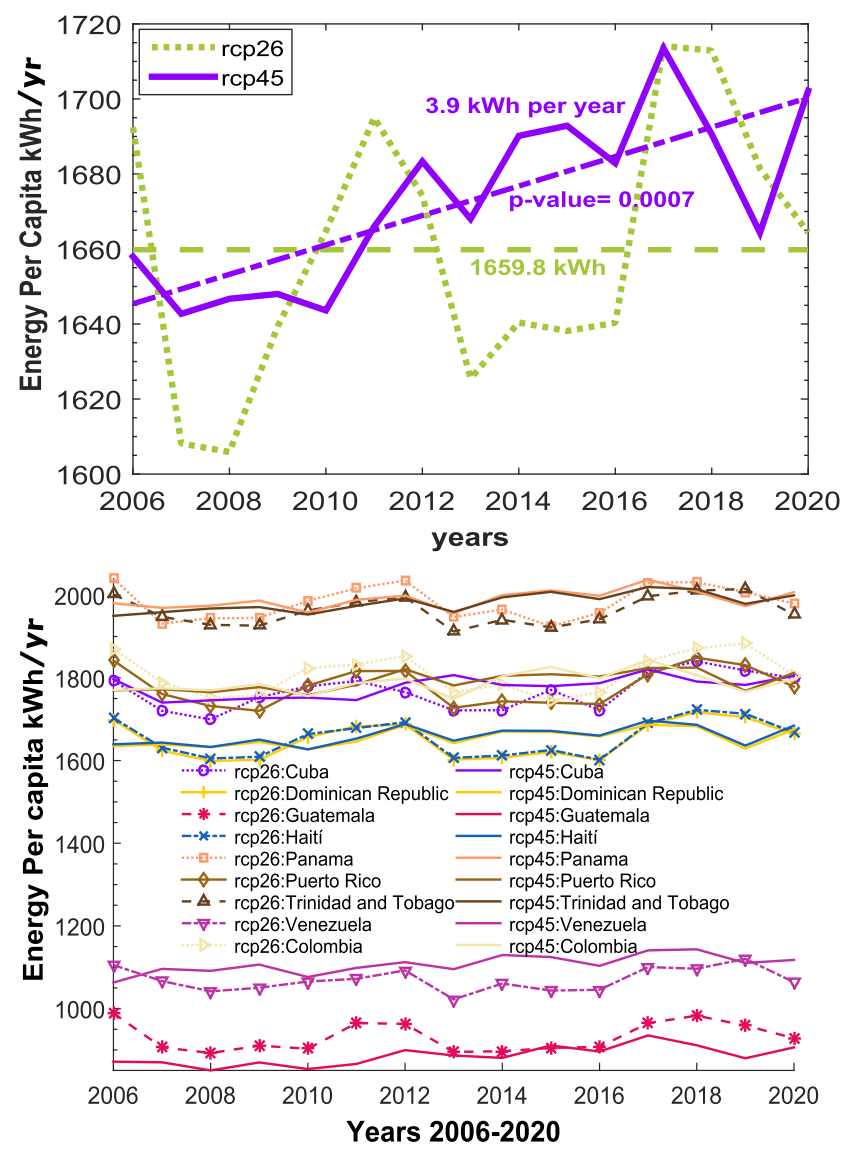

Fig. 8 Multi-model ensemble analysis for a annual energy demand per capita (kWh/year) averaged over the IAR and $\mathbf{b}$ annual energy demand per capita for main Caribbean countries in the IAR $(\mathrm{kWh} /$ year $)$ 

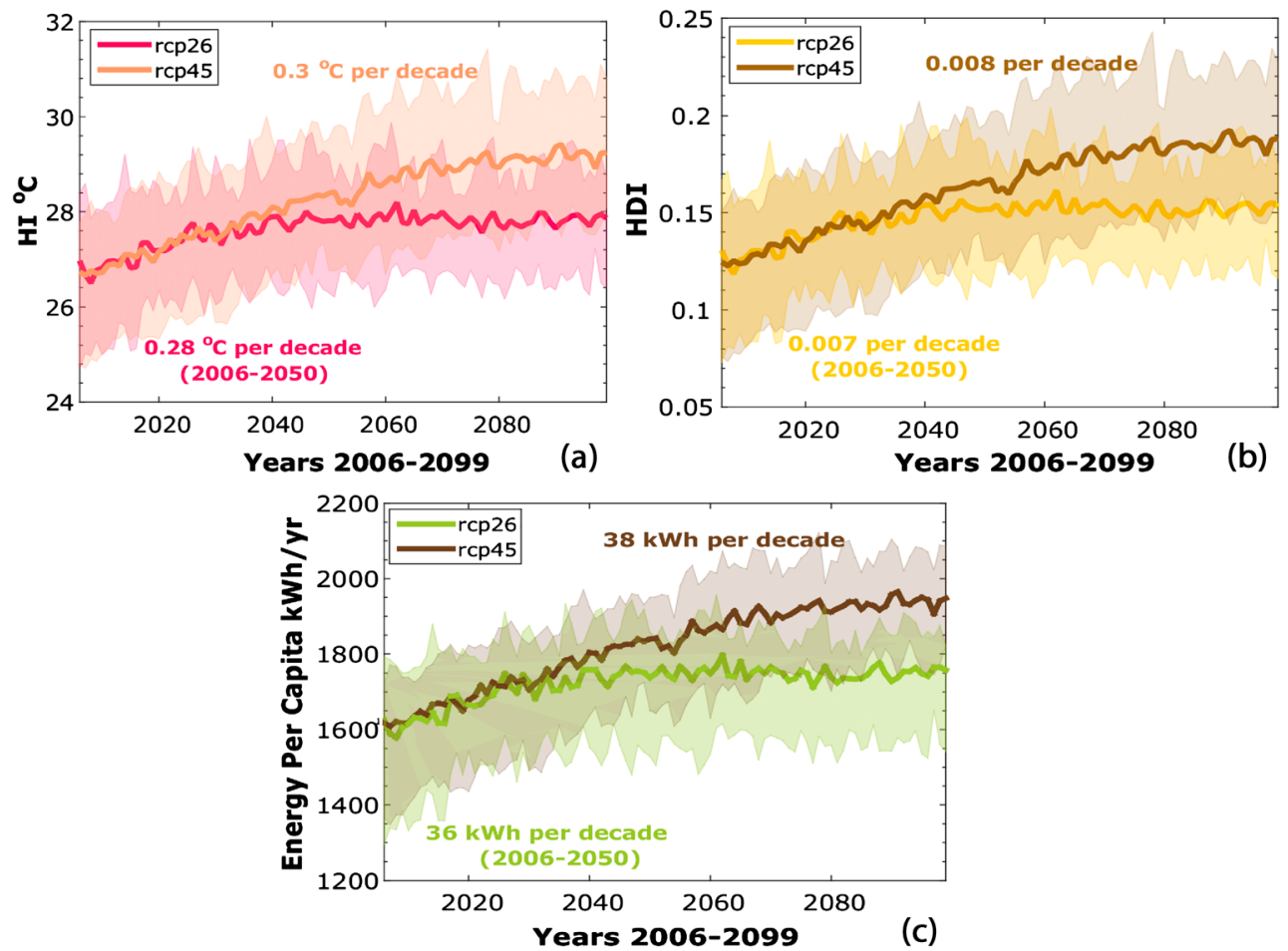

Fig. 9 Mean multi-model ensemble (continuous line) from 2006 to 2099 and bandwidth simulated by four GCMs under the RCP2.6/RCP4.5 scenarios for $\mathbf{a}$ heat index in ${ }^{\circ} \mathrm{C}, \mathbf{b} \mathrm{HDI}$, and $\mathbf{c}$ energy per capita in $\mathrm{kWh} /$ year

compared. The energy demand increase of these future climates with respect to the current climate has the same monthly
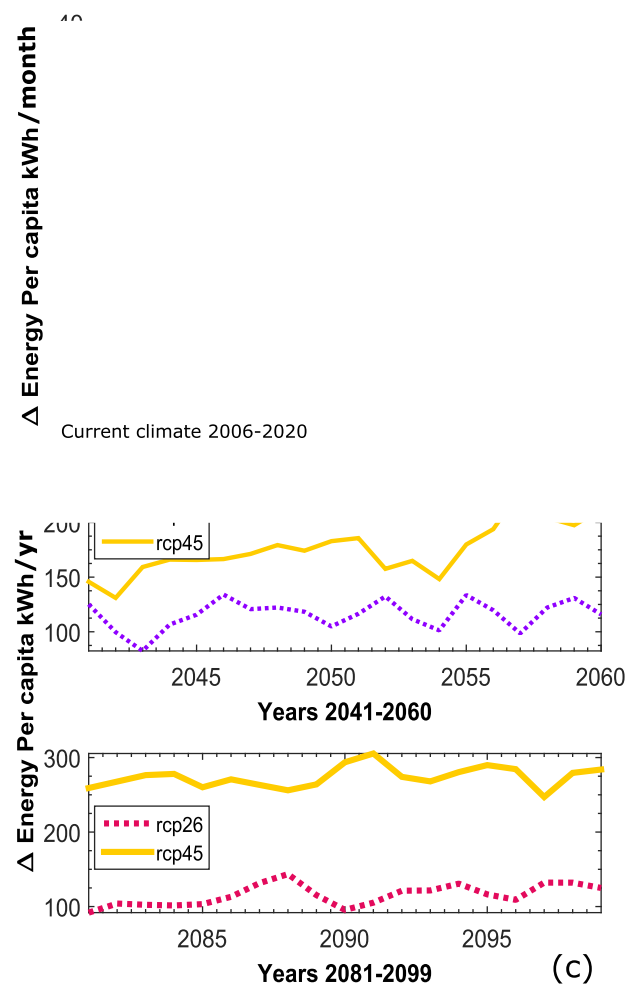

Fig. 10 Energy demand difference between future climate 2041-2060, 2081-2099, and current climate 2006-2020 for a monthly variation$\mathrm{kWh} /$ month, b spatial distribution for LRS-kWh/month, c annual mean value of $9.63 \mathrm{kWh}$ (see Fig. 10a). The RCP2.6/RCP4.5 scenario has a population rate increase of 1.25/1.24 until 2020
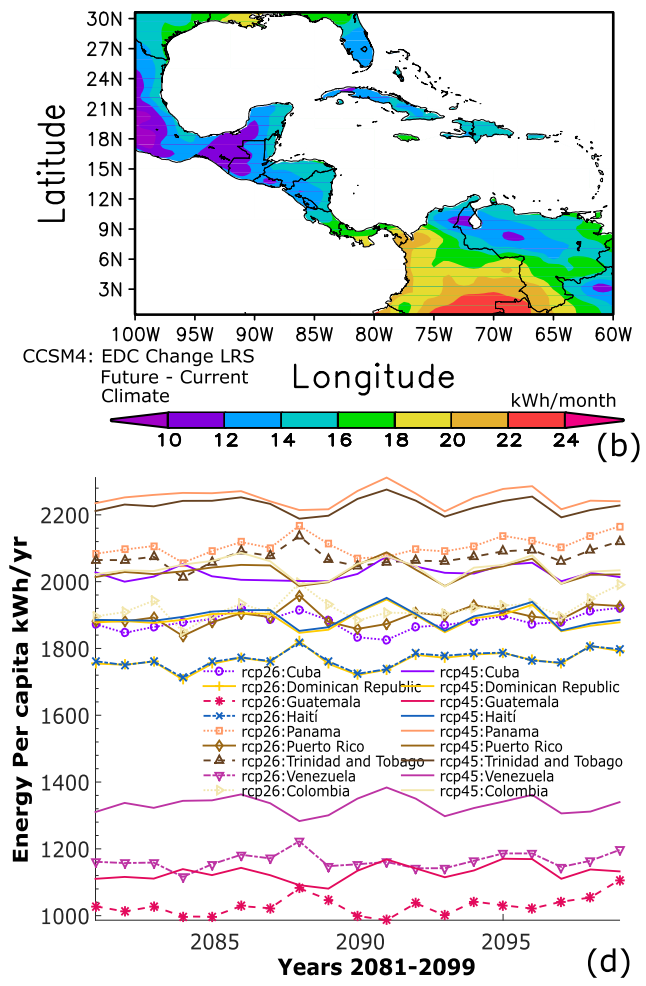

anomaly calculated as the difference between the annual future variation and the annual mean current climate-kWh/year, and $\mathbf{d}$ annual energy demand per capita for main countries in the IAR-kWh/year 
and $1.5 / 1.38$ in the last two decades of the twenty-first century (Vuuren et al. 2011). Assuming the total current population in the IAR (114.1 M inhabitants) follows these rates of increase, the total population has been projected in $2020(142 / 141 \mathrm{M}$ inhabitants) and 2099 (171/157M inhabitants). These projected populations along with the EDC for HVAC systems allow for a first-order calculation of the total energy demand in the "first" and "second" future climate periods. The larger energy demand in the scenario RCP4.5 and in the last two decades of the twenty-first century (2081-2099) may lead to an average in $8.15 \mathrm{GW}$ of additional power requirements with respect to the current climate, while the RCP2.6 scenario requires lower additional power requirement in the last two decades (7.57 GW higher than the current climate).

The geographical energy demand distribution across the IAR indicates more intense energy change in the LRS and centered on the Panama and the Colombia's Caribbean coastline. The EDC changes range from 18 to $22 \mathrm{kWh}$ per month, in agreement with a future Caribbean regional warming. Although the Greater Antilles are affected by the Atlantic warm pool, the easterly winds refresh the region, causing a lower energy per capita change (12-16 kWh per month) than the Northwest South American coastline (see Fig. 10b). Furthermore, Central America and Venezuela have similar changes in energy requirements, while Northern and Southern Mexico are characterized with lower EDC increases (less than $10 \mathrm{kWh}$ per month). Annual energy per capita anomalies for the two future climates point to a more intense energy per capita demand at the end of the twenty-first century in the RCP4.5 scenario (see Fig. 10c), with positive energy changes of approximately $274 \mathrm{kWh}$ per year, which is almost 1.6 times the anomaly from 2041 to 2060 . The RCP2.6 scenario does not show relevant changes when these two future climates are compared, with an annual mean of $115 \mathrm{kWh}$ (see Fig. 10c). At the end of the twenty-first century, the major countries show a similar variability than in the current climate but with higher intensity. In the RCP4.5 scenario, 7 of 9 countries have (on average) higher energy per capita requirements than the current climate, with a variation between 1887 and $2252 \mathrm{kWh}$ per year. The RCP2.6 scenario denotes a cooler environment, and in consequence, only 4 of 9 countries have an energy demand between 1887 and $2252 \mathrm{kWh}$ per year (see Fig. 10d).

The energy demand for all the studied countries for scenarios RCP2.6/RCP4.5 show an energy per capita increase between 5.68/12.4 and 10.57/27\%. Guatemala and Venezuela will likely have larger energy demands in a future warmer region, requiring $10.57 / 27.43$ and $8.8 / 20.3 \%$ more EDC than current climate (see Table 1). Thereby, the RCP4.5 scenario points to a future with more energy generation requirements than the RCP2.6 scenario. In addition, no significant trends were detected in the last two decades of the twenty-first century, in accordance with the RCP4.5 scenario tendency to stabilize the greenhouse gas concentrations in the atmosphere (the last decades). The RCP8.5 scenario was included in this portion of the analysis to identify how much energy is required in the warmest scenario. This scenario depicts the largest energy demand with an increase between 31 and $62.5 \%$ with respect to the current climate. Therefore, a better energy infrastructure could be a high priority to maintain adequate human comfort levels.

Effects of current and future climate disruptions could impact energy demands and costs. In view of this situation, the US Department of Energy (DOE) Building Technologies Office (BTO), in partnership with the HVAC industry, have been actively working to develop highly efficient systems, projecting energy savings of 12 and $14 \%$ in the years 2020 and 2030, respectively (Bansal et al. 2012; Wang et al. 2017). Technologies explored including solid-state cycles using magnetic refrigeration system, nanoscale energy savings materials, and electro-mechanical technologies (i.e., membrane heat pump) are proposed to improve heat transfer processes and building energy efficiency. Although these new technologies and materials are in the research stage, energy consumption reduction of $27 \%$ is estimated (Goetzler et al. 2014a, b). Furthermore, building materials such as phase change materials integrated in building structures could reduce the energy requirement for HVAC systems. These new materials and techniques could reduce the energy demand increases in tropical coastal areas due to global warming with the additional positive impact of reducing greenhouse gas emissions. As a future work, GCMs could incorporate these lower energy consumption strategies modifying the radiative forcing due to a reduction in the greenhouse gas emission to the atmosphere. The less intense radiative forcing could impact the air temperature trend simulated by GCMs in the IAR, reducing the amount of EDC needed to cool down buildings.

\section{Summary and conclusions}

This study performed a trend analysis for the spatial and temporal distributions of energy demand per capita and human comfort in the intra-Americas region as a response to recently observed regional warming trends. The environmental energy analysis was based on $\mathrm{HI}$ and a newly defined human discomfort index. EDC projections were obtained using a mean multi-model ensemble of four GCMs.

Results show that the IAR could be defined as a region with cooling needs to achieve human comfort in buildings, with the highest HDI in August leading to a maximum energy requirement for air conditioning systems. Southern Greater Antilles point to an EDC increase at an annual rate of change of 2 $3 \mathrm{kWh}$ per year (1980-2013), while inland South America has an increasing trend ranging between 1 and $5 \mathrm{kWh}$ per year, with exception of the Caribbean South America and Central 


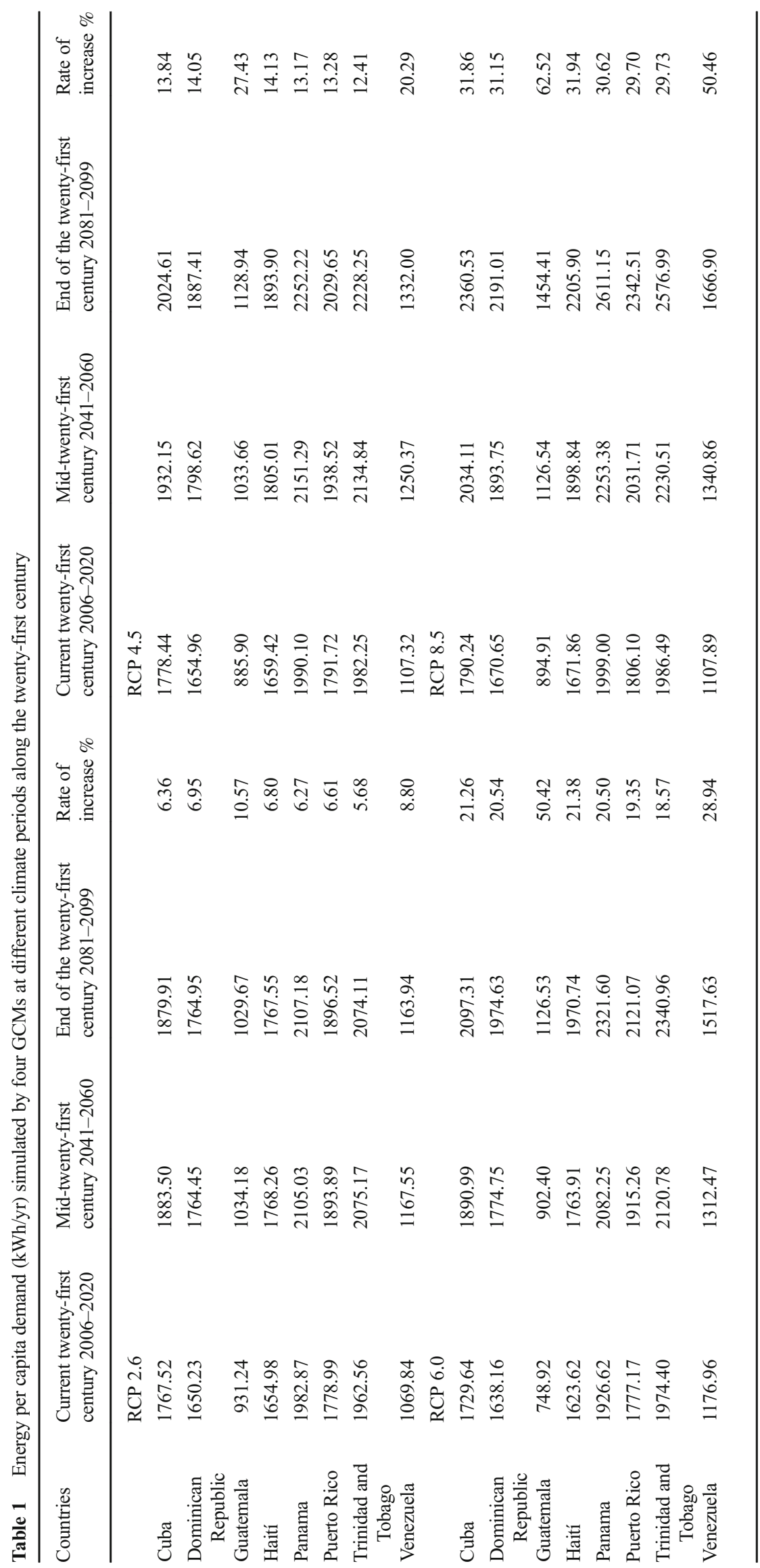


America where they have no trends. Puerto Rico and the Dominican Republic exhibit similar energy patterns with rates of change of 2.5 and $3.0 \mathrm{kWh}$ per year, respectively. According to electrical energy consumption data from the World Bank, Haiti has the lowest energy consumption in the region, but it is among the countries with highest energy per capita requirement for air conditioning systems.

Using GCMs, energy projections in the IAR for the twentyfirst century using the RCP2.6/RCP4.5 scenarios evidenced a positive EDC change around 9.6/15 $\mathrm{kWh}$ per month at the middle of this twenty-first century and $9.6 / 23 \mathrm{kWh}$ per month at the end of the century, which may translate to $7.57 / 8.15 \mathrm{GW}$ of additional power requirement. The intense energy demand intensification is in agreement with a warmer future climate change projected by the GCMs and IPCC scenarios. In the future climate, the largest energy demand change occurs during the LRS over Panama and Colombia's Caribbean coastline (18-22 kWh per month). At the end of the twenty-first century and in the RCP2.6/RCP4.5 scenarios, 4 of 9/7 of 9 IAR countries have EDC ranging between 1887 and $2252 \mathrm{kWh}$ per year, representing an energy demand per capita increase between 5.68/12.4 and $10.57 / 27 \%$ with respect to current climate. The higher $\mathrm{CO}_{2}$ emission scenario (RCP8.5) shows much larger energy increases than RCP4.5, with an increase between 31 and $62.5 \%$ with respect to the current climate. As a result, more energy production and improved energy infrastructure will be required to maintain demands for human comfort needs in buildings and for mitigation of future climate change impacts on public health at the end of the twenty-first century.

To mitigate the impacts on energy demands due to a warmer climate in tropical coastal regions, future high efficiency HVAC technologies may be used such as those proposed by the US DOE. These include new working fluids in HVAC and phase change materials within building structures. Therefore, the energy demand increased due to a warming climate could be mitigated with the added positive effect of lowering greenhouse gas emissions from tropical coastal regions. Therefore, future works will explore introducing the impacts of these new technologies in the EDC projected by GCMs. In addition, local records will be studied to identify HI, HDI, and energy per capita trends at the city and community levels and to correlate the HDI with countries' productivity. Correlations of peak energy demands with extreme heat wave events will also be explored.

CCSM4, Community climate system model version 4; CLM4, Community land model version 4; CLLJ, Caribbean low level jet; CMAP, CPC Merged analysis of precipitation; $C P C$, Climate prediction center; $D S$, Dry season; $E R S$, Early rainfall season; $G C M$, General circulation model; $H I$, Heat index; $H D I$, Human discomfort index; $H V A C$, Heating, ventilation, and air conditioning; IAR, Intra-Americas region; $I P C C$, Intergovernmental panel on climate change; $L R S$,
Late rainfall season; $M D R$, Main development region; NAHPS, North Atlantic high pressure system; NCEP, National center for environmental prediction; NOAA, National oceanic and atmospheric administration; $R C P$, Representative concentration pathways; $R H$, Relative humidity; SST, Sea surface temperature; VWS, Vertical wind shear

Acknowledgments The analysis was conducted at the highperformance computing facilities at City College of New York. This work was also sponsored by the National Oceanic and Atmospheric Administration, Office of Education Partnership Program award NA11SEC4810004, by the US Agency for International Development (USAID) under Cooperative Agreement Number AID-517A15-00002 and the US National Foundation Grant No CBET. 1438324.

Open Access This article is distributed under the terms of the Creative Commons Attribution 4.0 International License (http:// creativecommons.org/licenses/by/4.0/), which permits unrestricted use, distribution, and reproduction in any medium, provided you give appropriate credit to the original author(s) and the source, provide a link to the Creative Commons license, and indicate if changes were made.

\section{References}

Akbari H, Davis S, Dorsano S, et al (1992) Cooling our communities, a guidebook on tree planting and light-colored surfacing. U.S. Environmental Protection Agency, Office of Policy Analysis, Climate Change Division, Washington, DC

Alva L, Gonzalez Cruz J, Hertz J (2005) Impact of construction materials in the energy consumption in homes in the Caribbean. ASME 2005 Int Sol Energy Conf 113-121. doi: 10.1115/ISEC2005-76188

Anderson B, Bell M, Peng R (2013) Methods to calculate the heat index as an exposure metric in environmental health research. Environ Health Perspect 121:1111-1119. doi:10.1289/ehp.1206273

Angeles M, Gonzalez J, Erickson D, Hernández J (2007) Predictions of future climate change in the caribbean region using global general circulation models. Int J Climatol 27:555-569. doi:10.1002/joc. 1416

Angeles M, Gonzalez J, Ramirez N et al (2010a) Origins of the Caribbean rainfall bimodal behavior. J Geophys Res 115:1-17. doi:10.1029/ 2009JD012990

Angeles M, Cruz G, Erickson D, Hernández J (2010b) The impacts of climate changes on the renewable energy resources in the Caribbean region. J Sol Energy Eng 132:1-13. doi:10.1115/1.4001475

ASHRAE Press (2007) Air-conditioning system design manual, Second edn. Butterworth-Heinemann, New York

Bansal P, Vineyard E, Abdelaziz O (2012) Status of not-in-kind refrigeration technologies for household space conditioning, water heating and food refrigeration. Int J Sustain Built Environ 1:85-101. doi:10. 1016/j.ijsbe.2012.07.003

Braun M, Altan H, Beck S (2014) Using regression analysis to predict the future energy consumption of a supermarket in the UK. Appl Energy 130:305-313. doi:10.1016/j.apenergy.2014.05.062

Calder W (2014) Australian energy projections to 2049-50. In: Bur. Resour. Energy Econ. http://www.industry.gov.au/Office-of-theChief-Economist/Publications/Documents/aep/aep-2014-v2.pdf. Accessed 26 Dec 2015

Carmona A, Poveda G (2014) Detection of long-term trends in monthly hydro-climatic series of Colombia through empirical mode decomposition. Clim Chang 123:301-313. doi:10.1007/s10584-013-1046-3

Comarazamy D, Gonzalez J, Luvall J (2013) Quantification and mitigation of long-term impacts of urbanization and climate change in the 
tropical coastal city of San Juan, Puerto Rico. Int J Low-Carbon Technol 10:87-97. doi:10.1093/ijlct/ctt059

Curtis S (2013) Daily precipitation distributions over the intra-Americas sea and their interannual variability. Atmósfera 26:243-259. doi:10. 1016/S0187-6236(13)71074-9

Curtis S, Gamble D (2008) Regional variations of the Caribbean midsummer drought. Theor Appl Climatol 94:25-34. doi:10.1007/ s00704-007-0342-0

Edwards EE, Iyare O, Moseley L (2012) Energy consumption in typical Caribbean office buildings: a potential short term solution to energy concerns. Renew Energy 39:154-161. doi:10.1016/j.renene.2011. 07.037

Epstein Y, Moran D (2006) Thermal comfort and the heat stress indices. Ind Health 44:388-398. doi:10.2486/indhealth.44.388

Folkins I, Braun C (2003) Tropical rainfall and boundary layer moist entropy. J Clim 16:1807-1820. doi:10.1175/1520-0442(2003) 016<1807:TRABLM $>2.0 . \mathrm{CO} ; 2$

Gamble D, Curtis S (2008) Caribbean precipitation: review, model and prospect. Prog Phys Geogr 32:265-276. doi:10.1177/ 0309133308096027

Gent P, Danabasoglu G, Donner L et al (2011) The community climate system model version 4. J Clim 24:4973-4991. doi:10.1175/ 2011JCLI4083.1

Glenn E, Comarazamy D, Gonzalez J, Smith T (2015) Detection of recent regional sea surface temperature warming in the Caribbean and surrounding region. Geophys Res Lett 42:6785-6792. doi:10.1002/ 2015GL065002

Goetzler W, Guernsey M, Young J (2014a) Research \& development roadmap for emerging HVAC technologies. U.S. Department of Energy, Building Technologies Office

Goetzler W, Zogg R, Young J, Johnson C (2014b) Alternatives to vaporcompression HVAC technology. ASHRAE J 56:12-23

Gonzalez J, Luvall J, Douglas R et al (2005) Urban heat islands developing in coastal tropical cities. EOS Trans Am Geophys Union 86: 397-412. doi:10.1029/2005EO420001

Gonzalez J, Sequera P, Molina Y, et al (2013) Climate and energy vulnerability in coastal regions: the case for US Pacific and Northeast Corridor coastal regions. In: Vulnerability of Energy to Climate, First Edition. Academic Press, Oxford Paris, pp 3-35

Gutiérrez E, Gonzalez J, Bornstein R et al (2013) A new modeling approach to forecast building energy demands during extreme heat events in complex cities. J Sol Energy Eng 135:1-7. doi:10.1115/ 1.4025510

Holland M, Bailey D, Briegleb B et al (2012) Improved sea ice shortwave radiation physics in CCSM4: the impact of melt ponds and aerosols on Arctic Sea ice. J Clim 25:1413-1430. doi:10.1175/JCLI-D-1100078.1

IPCC (2013) Climate change 2013: the physical science basis. Contribution of working group I to the fifth assessment report of the Intergovernmental panel on climate change. Cambridge University Press, Cambridge and New York

Irena (2012) Renewable energy country profiles for the Caribbean. In: Int. Renew. Energy Agency. http://www.irena.org/menu/index.aspx? $\mathrm{mnu}=$ Subcat $\&$ PriMenuID $=36 \&$ CatID $=141 \&$ SubcatID $=223$. Accessed 18 Jan 2016

Magaña V, Caetano E (2005) Temporal evolution of summer convective activity over the Americas warm pools. Geophys Res Lett 32:1-4. doi:10.1029/2004GL021033

Mapes B, Liu P, Buenning N (2005) Indian monsoon onset and the Americas midsummer drought: out-of-equilibrium response to smooth seasonal forcing. J Clim 18:1109-1115. doi:10.1175/JCLI3310.1

McIntyre A, El-Ashram A, Ronci M, et al (2016) Caribbean energy: macro-related challenges. In: Int. Monet. Fund. https://www.imf. org/external/pubs/cat/longres.aspx?sk=43776.0. Accessed 17 Apr 2016
Mohan M, Gupta A, Bhati S (2014) A modified approach to analyze thermal comfort classification. Atmospheric Clim Sci 4:7-19. doi: 10.4236/acs.2014.41002

Moran J (2002) Online weather studies, Second edn. American Meteorological Association, Boston

Moran D, Pandoll K, Shapiro Y et al (2001) An environmental stress index (ESI) as a substitute for the wet bulb globe temperature (WBGT). J Therm Biol 26:427-431. doi:10.1016/S0306-4565(01) 00055-9

Moss R, Babiker M, Brinkman S et al (2008) Towards new scenarios for analysis of emissions, climate change, impacts, and response strategies. Technical Summary. Intergovernmental Panel on Climate Change, Geneva

NOAA (2014) What is the heat index? In: Natl. Weather Serv. Weather Forecast Off. http://www.srh.noaa.gov/ama/?n=heatindex. Accessed 30 Jun 2015

NWS (2014) The heat index equation. In: Natl. Weather Serv. Weather Predict. Cent. http://www.wpc.ncep.noaa.gov/html/heatindex equation.shtml. Accessed 1 Jul 2015

Persily A, Bulter D, Alevantis L, et al (2003) ASHRAE standard. Ventilation for acceptable indoor air quality. American Society of Heating, Refrigerating and Air-Conditioning Engineers, Atlanta USA

Rahman A, Begum M (2013) Application of non parametric test for trend detection of rainfall in the largest island of Bangladesh. ARPN J Earth Sci 2:40-44 2305-493X

Stavins RN, Stowe RC (eds) (2016) The Paris agreement and beyond: International climate change policy post-2020. Cambridge, Massachusetts: Harvard Project on Climate Agreements, Belfer Center, pp 1-114. http:/www.belfercenter.org/publication/parisagreement-and-beyond-international-climatechange-policy-post2020. Accessed 15 Mar 2017

Steadman R (1979) The assessment of sultriness. Part I: a temperaturehumidity index based on human physiology and clothing science. J Appl Meteorol 18:861-873. doi:10.1175/1520-0450(1979) 018<0861:TAOSPI $>2.0$. CO;2

Stull R (2000) Meteorology for scientists and engineers, Second edn. Brooks/Cole, Belmont

Taylor M, Enfield D, Chen A (2002) Influence of the tropical Atlantic versus the tropical pacific on Caribbean rainfall. J Geophys Res 107: 10-1-10-14. doi:10.1029/2001JC001097

Taylor K, Stouffer R, Meehl G (2012) An overview of CMIP5 and the experiment design. Bull Am Meteorol Soc 93:485-498. doi:10. 1175/BAMS-D-11-00094.1

Tejeda A, Garcia O (2002) A comparative simple method for human bioclimatic conditions applied to seasonally hot/warm cities of Mexico. Atmósfera 15:55-56 0187-6236

The World Bank (2015) Electric power consumption. In: World Bank Group. http://data.worldbank.org/indicator/EG.USE.ELEC.KH.PC. Accessed 15 Dec 2015

U.S. Department of Energy (2009) 2008 Buildings energy data book. In: Energy Effic. Renew. Energy. http://buildingsdatabook.eren.doe. gov/docs/DataBooks/2008_BEDB_Updated.pdf. Accessed 12 Mar 2016

U.S. Environmental Protection Agency (2015) Energy and the environment. In: End-Users Electr. https://www.epa.gov/energy/end-userselectricity. Accessed 15 Mar 2016

Vuuren D, Edmonds J, Kainuma M et al (2011) The representative concentration pathways: an overview. Clim Chang 109:5-31. doi:10. 1007/s10584-011-0148-z

Wang N, Phelan P, Gonzalez J, et al (2017) Ten questions concerning future buildings beyond zero energy and carbon neutrality. Build Environ 1-14. doi: 10.1016/j.buildenv.2017.04.006

Zhang Q, Singh V, Sun P et al (2011) Precipitation and streamflow changes in China: changing patterns, causes and implications. J Hydrol 410:204-216. doi:10.1016/j.jhydrol.2011.09.017 